\title{
TRATAMENTO DOS CASOS GRAVES DE MIASTENIA. AÇÃO DO ACTH E CORTISONA. CONSIDERAÇÕES A PROPóSITO DE TRES CASOS
}

\author{
JosÉ LAMARTine dE ASSIS *
}

Até hoje o tratamento da miastenia grave constitui sério problema para o neurologista. A patogenia da doença permaneceu completamente obscura até o conhecimento da teoria do mediador químico dos impulsos nervosos nas sinapses, resultando a doença da diminuição da síntese da acetilcolina na junção mioneural.

$\dot{E}$ aceito pela maioria dos autores que a liberação da acetilcolina é necessária na transmissão dos impulsos nervosos. A certeza de que a prostigmina assegura a ação da acetilcolina na sinapse serviu de base para o primeiro tratamento realmente eficaz da miastenia ${ }^{x}$.

Entretanto, embora seja êste o conceito mais adequado para explicar a doença, não há prova conclusiva para o mesmo. Nestas condições, a prostigmina e seu similar mais recente - peridostigmina ${ }^{2}$ - embora não representem as drogas ideais, são ainda os medicamentos de eleição para combater os sintomas miastênicos. Várias outras drogas foram experimentadas na miastenia grave, destacando-se o cloreto de 3-hidroxifenildimetilamônio 3,4,5 (tensilon), o tetraetilpirofosfato ${ }^{6}$ ( $\mathrm{T}$ e PP), a octametilpirofosforamida 7,8 (OMPA) e o hidrocloreto de guanidina 9, 10; tôdas estas drogas são menos usadas que a prostigmina, pois são de manejo terapêutico mais difícil e de baixo limiar tóxico. A efedrina ${ }^{11}$, que vinha sendo empregada antes mesmo da descoberta de Walker 1, é um dos principais medicamentos adjuvantes, ao lado do cloreto de potássio.

Além das pesquisas no terreno exclusivo da terapêutica química, os autores procuraram estudar as possiveis relações da miastenia grave com is glândulas de secreção interna. Neste particular Torda e Wolff 12,13,14 e 15, Dougherty e White, e Simpson e col. (cit. por Torda e Wolff 16), obtiveram resultados animadores em trabalhos experimentais feitos a partir de 1943. Assim, a função neuromuscular e a síntese da acetilcolina foram estudadas através da hipofisectomia em animais ${ }^{15}$, das injeções de sôro de indivíduos miastênicos ${ }^{13}$ ou das injeções de extratos glandulares 12, 14 .

Com estas pesquisas foram estabelecidas as bases fisiológicas para um novo método de tratamento da miastenia grave. Assim é que, antes mesmo

Trabalho da Clínica Neurológica da Fac. Med. da Univ. de São Paulo (Prof. A. Tolosa). Entregue para publicação em agôsto 1955.

* Docente Livre. 
do público conhecimento dos extraordinários efeitos dos hormônios glicocorticóides, Torda e Wolff ${ }^{16}$ empregaram, pela primeira vez, o ACTH no tratamento de pacientes com miastenia grave. A partir de 1948 surgiram numerosos trabalhos sôbre o efeito do ACTH e da cortisona nesta doença e em outras miopatias. Assim, Soffer ${ }^{17}$, Millikan e Eaton 18, 19 e Schlezinger ${ }^{20}$ obtiveram resultados favoráveis que, em geral, apareciam após a suspensão da droga mas não eram permanentes; além disso, não eram todos os pacientes que se beneficiavam com o tratamento. Torda e Wolff ${ }^{21,22}$, mais reccntemente, repetiram os trabalhos experimentais (hipofisectomias), e fizeram novos estudos clínicos e bioquímicos, verificando principalmente a capacidade de síntese da acetilcolina pelo sôro sangüíneo, antes e depois do emprêgo do ACTH. Êstes autores concluíram por uma diminuição da sintese da acetilcolina e da capacidade do nervo em manter a função muscular nas pacientes com miastenia grave; ainda mais, o ACTH teria um efeito especifico no mecanismo responsável pela doença, aumentando a síntese da acetilcolina e dificultando a ação da colinesterase.

Entretanto, ao contrário de todos os autores até aqui citados, Ritter e Epstein ${ }^{23}$ e Shy e col. ${ }^{24}$, observaram piora das manifestações clínicas em pacientes miastênicos tratados pelo ACTH ou pela cortisona. É de notar que todos êsses autores utilizaram o ACTH de modo arbitrário, em doses variáveis, mas em geral altas, por via muscular, em curas com intervalos diversos de tempo. Os resultados obtidos com a cortisona eram sempre menos favoráveis que com o ACTH.

\section{OBSERVACCOES}

Caso 1 - B. A., branco, brasileiro, solteiro, 28 anos, examinado em 16-5-53 (reg. 169.681). História clinica: Dificuldade para deglutir, para mastigar os alimentos sólidos e para ocluir as pálpebras; cansaço fácil nos membros. Doença de início insidioso (há 4 anos) e de evolução progressiva, com acentuado emagrecimento. Jamais houve remissão espontânea dos sintomas que, entretanto, remitiam satisfatōriamente, no comêço da doença, com o uso da prostigmina; contudo os sintomas foram se tornando resistentes a êste medicamento e a outras arogas. Nestas condições, apesar do uso da prostigmina, os sintomas foram se acentuando cada vez mais e se estendendo do segmento cefálico para os membros. Exame neurológico: Apocamnose intensa e muito nitida no segmento cefálico; o facies apresenta o aspecto miastênico com predominância dos distúrbios nos territórios musculares dos nervos oculomotores, trigêmeo, facial, glossofaríngeo, pneumogástrico e grande hipoglosso; a voz é anasalada, quase incompreensível e em tom murmurativo. Exames subsidiários - Exame de líqüido céfalo-raquidiano, em punção suboccipital, normal. Reações de Wassermann, Kahn e Kline, no sangue, negativas. Eletrodiagnóstico normal; não foi obtida a reação miastênica de Jolly. Exame otoneurológico: déficit motor nos territórios musculares do $3^{\circ}, 5^{\circ}, 7^{\circ}, 9^{\circ}, 10^{\circ}$ e $12^{\circ}$ nervos cranianos.

Evoluçăo e tratamento - Agravação rápida do quadro miastênico, com graves distúrbios respiratórios apesar do uso intensivo da prostigmina ( $30 \mathrm{mg} 8$ a 10 vêzes ao dia), sendo necessárias a aspiração brônquica e o uso do oxigênio. Como persistissem os sinais e sintomas da miastenia com insuficiência respiratória, foi instituido o tratamento pelo ACTH por via intravenosa, gôta a gôta, em sôro glicosado isotônico. A seqüencia do tratamento pelo ACTH foi a seguinte: nos primeiros 4 dias foram administrados $12,5 \mathrm{mg}$ por dia; a seguir $10 \mathrm{mg}$ por dia durante 6 dias 
e $8 \mathrm{mg}$ durante 12 dias; como houvesse ligeira agravação dos sintomas, a dose diária foi elevada para $10 \mathrm{mg}$ e assim mantida por mais 12 dias; como não houvesse melhora, a dose foi novamente elevada para $15 \mathrm{mg}$ diários, dose esta mantida por 27 dias, o que permitiu a remissão total do quadro miastênico; depois, a dose foi diminuida para 10 e $5 \mathrm{mg}$ até a alta hospitalar, dada em 30-7-53. A dose total de ACTH foi de $751 \mathrm{mg}$, em 64 dias. O enfêrmo teve alta em condições excelentes, tanto gerais como quanto aos sintomas miastênicos. E de notar que, na primeira semana do tratamento pelo ACTH, houve acentuada agravação da apocamnose, seguida de melhora evidente, rápida e progressiva até remissão total.

o paciente passou perfeitamente bem durante o primeiro mês após o término desta primeira série de $\mathrm{ACTH}$. Depois reapareceram os sintomas miastênicos no território muscular dos nervos cranianos, porém com pouco intensidade e assim permaneceram até 12-54. Desta data em diante a sintomatologia foi se agravando, porém sem nunca igualar ao quadro que obrigou à internação urgente no ano de 1953. Como não houvesse melhora dos sintomas com o uso da prostigmina em doses altas, o enfêrmo foi reinternado em 8-3-55, não só para ser tentada nova remissão do quadro miastênico, como, também, para ser estudada a dose de manutenção. A seqüência da segunda série de tratamento foi a seguinte: ACTH em sôro glicosado a $5 \%$ em gôta a gôta na veia, durante 21 dias; foram administrados 12,5 mg nos primeiros 10 dias, $10 \mathrm{mg}$ durante uma semana, $8 \mathrm{mg}$ durante mais 3 dias e $5 \mathrm{mg}$ nos 2 últimos dias; a seguir foi iniciada a administração da dose de manutençāo de $5 \mathrm{mg}$, em dias alternados (5 aplicaçōes), depois cada 2 dias ( 7 aplicações) e, finalmente, cada 3 dias (4 aplicações). Alta em excelentes condiçōes gerais e com remissāo total dos sintomas miastênicos. A dose total do ACTH foi de $299 \mathrm{mg} \mathrm{em}$ 37 dias de tratamento efetivo. Ao paciente foi indicado continuar a usar a dose de manutenção fora do hospital. O período de internação dêste enfêrmo foi de 113 dias.

CAso 2 - A. B., branca, brasileira, solteira, 20 anos, examinada em 17-6-53 (reg. 310.905). História clinica: Fraqueza e fadiga muscular, especialmente no segmento cefálico. A doença iniciou-se há 2 anos e teve evolução progressiva; houve um período de regressão espontânea de apenas um mēs e meio no comêço da doença. Em princípios do ano de 1953 começou a usar a prostigmina, com sucesso; entretanto, nestes últimos 3 meses começou a piorar apesar do uso daquele medicamento, surgindo diplopia e agravando-se a ptose palpebral bilateral e os distúrbios da fala, da respiração e da deglutição; ao mesmo tempo os movimentos ativos para levantar-se e sentar-se no leito tornaram-se impraticáveis. A timectomia então feita veio agravar ainda mais a sintomatologia. Exame neurológico: Fadiga muscular intensa e generalizada, predominando no segmento cefálico. Facies miastennico (fig. 1). Voz anasalada, dificil, incompreensivel e em tom murmurativo. Bôca entreaberta, deixando escorrer saliva pelos cantos. A paciente não se senta sózinha no leito. Ao deitar-se, o tronco e a cabeça caem para trás sem qualquer reação de defesa. Regime geral de hipotonia muscular e hiporreflexia. Ptose palpebral. Lingua quase inerte na bôca. Mastigação e deglutição impraticáveis, sendo necessária a alimentação por sonda. Exames subsidiários - Exame do líqüido céfalo-raquidiano, em punção suboccipital, normal. Hemossedimentaşöo de $6 \mathrm{~mm}$, na primeira hora. Exame hematológico: desvio à esquerda; neutrófilos com granulações tóxicas; eosinofilia (5\%). Eletrodiagnóstico normal; não foi obtida a reação miastênica de Jolly. Eletrencefalograma normal.

Tratamento e evoluçäo - Poucas melhoras foram conseguidas com o uso da prostigmina nas doses de 75 a $150 \mathrm{mg}$ diárias, nos primeiros dias de hospitalização. Cinco dias após o início do ACTH (12,5 $\mathrm{mg}$ por dia), houve piora rápida dos sintomas a ponto de terem sido necessárias a aspiração brônquica e a traquestomia. A seqüência da primeira série de tratamento pelo ACTH foi a seguinte: ACTH em sôro glicosado a $5 \%$ em gôta a gôta na veia, diàriamente, durante 93 dias; nos primeiros 3 dias, 12,5 $\mathrm{mg}$ por dia; a seguir, $15 \mathrm{mg}$ durante 16 dias, depois $20 \mathrm{mg}$ durante 21 dias; em seguida as doses foram baixadas lenta e progressivamente para 15, 12,5, 10 e $8 \mathrm{mg}$ num prazo de 3 semanas; finalmente, foram mantidos 10 mg diários 
como dose de manutenção até a alta hospitalar que ocorreu em 19-9-53. A dose total do ACTH foi de $1057,5 \mathrm{mg}$, em 93 dias de tratamento.

A enfêrma passou muito bem no primeiro mês depois da alta, tendo reassumido suas atividades profissionais (datilógrafa). Manteve-se relativamente bem com 0 uso do cortone por via oral ou muscular, a partir do segundo mês após a alta hospitalar até poucas semanas antes da segunda internação. Esta foi condicionada por agravação séria da miastenia. Como acontecera na primeira hospitalização, a paciente foi internada em estado geral precário, por isso que nas últimas semanas tivera sua deglutiçāo bastante comprometida e se alimentara de modo deficiente. Houve, como na primeira série do ACTH, agravação alarmante dos sintomas na primeira semana de tratamento. A seqüência da segunda série do tratamento pelo ACTH foi a seguinte: ACTH em sôro glicosado a $5 \%$ em gôta a gôta na veia, diàriamente, durante 36 dias; foram administrados $15 \mathrm{mg}$ nos primeiros 6 dias; como tivesse havido agravaçāo da sintomatologia, a dose foi elevada para $25 \mathrm{mg}$ diários até o $12^{\circ}$ dia; ulteriormente passou a ser de $12,5 \mathrm{mg}$ durante 10 dias; da terceira semana de tratamento em diante as doses foram diminuidas para $10 \mathrm{mg}$, porém tiveram que ser novamente elevadas para $12,5 \mathrm{mg}$ uma semana depois, em virtude do aparecimento de discretos distúrbios na deglutiçāo e na fala; esta última dosagem foi mantida como dose de manutenção até a alta hospitalar que ocorreu em 15-1-54. A dose total do ACTH foi de $642,5 \mathrm{mg}$ em 36 dias de tratamento. A paciente saiu do hospital em excelentes condições clinicas e gerais, com remissão quase total. Restava ligeira dificuldade na deglutição apesar do uso continuado, embora em dose muito baixa, da prostigmina (3 comprimidos ao dia). Como medida de precaução foi mantida a traqueostomia $\mathrm{e}$ indicado o uso do cortone por via muscular.

A paciente manteve-se relativamente bem até algumas semanas antes da terceira internação, condicionada, como as anteriores, por rápida acentuação do quadro miastênico, com impressionante repercussão para o lado do estado geral. A última internação ocorreu em 10-12-54, ocasião em que houve necessidade de oxigênio e de administração de prostigmina na veia, em virtude de dispnéia e impossibilidade de deglutiçăo; a paciente mantinha-se completamente imobilizada no leito. A sintomatologia pouco ou quase nada se modificou com doses elevadas de prostigmina usada por tôdas as vias. Após a primeira semana de ACTH as melhoras começaram a aparecer e foram se acentuando de modo lento, mas progressivo. Como das outras vêzes, na primeira semana do tratamento pelo ACTH houve agravação dos sintomas a ponto de se pensar no emprêgo do respirador artificial. Após um mês de tratamento as condiçỏes gerais e neurológicas eram excelentes, o pêso da paciente aumentou de 13 quilos; restavam, ainda, incompleto fechamento das pálpebras e ligeira alteração na deglutição. A seqüência desta terceira série do tratamento pelo ACTH foi a seguinte: ACTH en sôro glicosado a $5 \%$ em gôta a gôta na veia, diàriamente, durante os primeiros 54 dias e, a seguir, em dias alternados e em cada 2 dias; nos primeiros 5 dias, $12,5 \mathrm{mg}$ por dia; no $6{ }^{\circ}$ dia $20 \mathrm{mg}$; nos 5 dias subseqüentes $12,5 \mathrm{mg}$; no $12^{\circ}$ dia $15 \mathrm{mg}$; nos 20 dias seguintes $12,5 \mathrm{mg}$; a partir do segundo mês $10 \mathrm{mg}$ por dia durante 10 dias, $8 \mathrm{mg}$ durante 4 dias e $5 \mathrm{mg}$ durante 10 dias; a partir do $25^{\circ}$ dia do segundo mès de tratamento iniciamos a dose de $2,5 \mathrm{mg}$ em dias alternados, fazendo 23 aplicaçōes; a seguir tentamos $5 \mathrm{mg}$ cada 2 dias, e terminamos a série com $5 \mathrm{mg}$ em dias alternados; esta última dosagem foi considerada de manutenção; a alta ocorreu em 19-4-55. O total de ACTH foi de 679,5 mg em 83 dias de tratamento efetivo. Nesta última hospitalização foram feitos os seguintes exames complementares: Radiografia do tórax, normal. Eletrocardiograma, normal. Dosagem de colesterol no sôro sangüineo: $124 \mathrm{mg}$ por $100 \mathrm{ml}$ (método de Sheftel com leituras espectrofotométricas). Dosagem do cálcio no sôro sangüineo: $8,8 \mathrm{mg}$ por $100 \mathrm{ml}$ (método titrimétrico de Clark-Collip, Kramer-Tistall). Fósforo inorgânico no sôro: $4,9 \mathrm{mg}$ por $100 \mathrm{ml}$ (método de Fiske-Subburow com leitura espectrofotométrica). Fosfatase alcalina no sôro: 4,6 unidades King-Armstrong por 100 $\mathrm{ml}$ (método de King-Armstrong, substrato de fenilfosfato dissódico de ph. 9,3 com leitura espectrofotométrica). Prova de tolerância à creatina (urina): 10 período, creatina $0,00 \mathrm{~g}$ por litro, creatinina $0,72 \mathrm{~g}$ por litro e 0,58 $\mathrm{g}$ no volume enviado $(800 \mathrm{ml}) ; 2^{\circ}$ periodo: creatina $0,37 \mathrm{~g}$ por litro e no volume enviado (1.000 $\left.\mathrm{ml}\right)$; 
creatinina $0,70 \mathrm{~g}$ por litro e no volume enviado $(1.000 \mathrm{ml})$. Dosagem da creatinina no sangue: $0,9 \mathrm{mg}$ por $100 \mathrm{ml}$ (método de Folin-Wer com leitura espectrofotométrica). Hemograma: 11.000 leucócitos por $\mathrm{mm}^{3} ; 76 \%$ de hemoglobina e desvio à esquerda. A enfêrma continua sob contrôle no ambulatório (fig. 1).

CASo 3 - C. A. S., branca, brasileira, casada, 49 anos. Examinada em 27-5-53 (reg. 000.904). História clínica - Diplopia e apocamnose nos quatro membros há 3 anos, com desordens da fala, da marcha, da mastigação e da deglutição. A paciente já estivera neste Hospital, com oftalmoplegia total e impossibilitada de andar e de ficar de pé; nessa ocasião, melhoras rápidas com a prostigmina, restando, porém, ptose palpebral e diplopia que persistem até hoje apesar do tratamento. Éstes distúrbios não impediram que a enfêrma exercesse suas atividades normais até a data da reinternação. Exame neurológico - Ptose das pálpebras mais acentuada em OD; leve enrugamento da fronte com ligeira inclinação da cabeça para trás, esboçando o facies de Hutchinson (fig. 2). Moderada fraqueza muscular nos quatro membros, mais evidente no superior esquerdo. Paresia dos músculos retos interno e externo em OD e de tôda musculatura extrinseca em OE. Exames subsidiários - Exame de líqüido céfalo-raquidiano, em punção suboccipital, normal. Exame hematológico: moderada anemia hipocrômica; $30 \%$ de eosinófilos. Fósforo inorgânico: $3,4 \mathrm{mg}$ por $100 \mathrm{ml}$. Eletrodiagnóstico: hipoexçitabilidade farádica e galvânica dos músculos mastigadores; não foi obtida a reação de Jolly. Exame neuro-ocular: ptose palpebral parcial mais intensa em OD; oftalmoplegia externa parcial direita (comprometimento do $3^{\circ}$ e $6^{\circ}$ pares), apenas funcionando os músculos reto superior e inferior; oftalmoplegia externa total em OE; pupila esquerda maior que a direita; reflexos pupilares normais; visão 0,7 em OD e 0,8 em OE.

Evoluçio e tratamento - A seqüência da série de tratamento pelo ACTH foi a seguinte: ACTH em sôro glicosado a $5 \%$ em gôta a gôta na veia, diàriamente, durante 22 dias; nos primeiros 7 dias foram feitos $12,5 \mathrm{mg}$ por dia; nos 15 dias restantes foram feitos $10 \mathrm{mg}$ por dia. A dose total de ACTH foi de $237,5 \mathrm{mg} \mathrm{em}$ 22 dias. A diplopia e a ptose palpebral desapareceram completamente, havendo correção total do estrabismo. $\dot{E}$ de notar-se que esta remissão completa da oftalmoplegia se verificou pela primeira vez nos 3 anos de doença e coincidiu com o tratamento pelo ACTH. A paciente passou bem cêrca de um mês depois de terminado o tratamento, porém, a sezuir, a diplopia e a ptose palpebral reapareceram, sendo esta última pouco evidente e apenas observável em OD. Nenhuma outra manifestação surgiu e a enfêrma vem exercendo até o presente momento tôdas as suas atividades habituais (fig. 2).
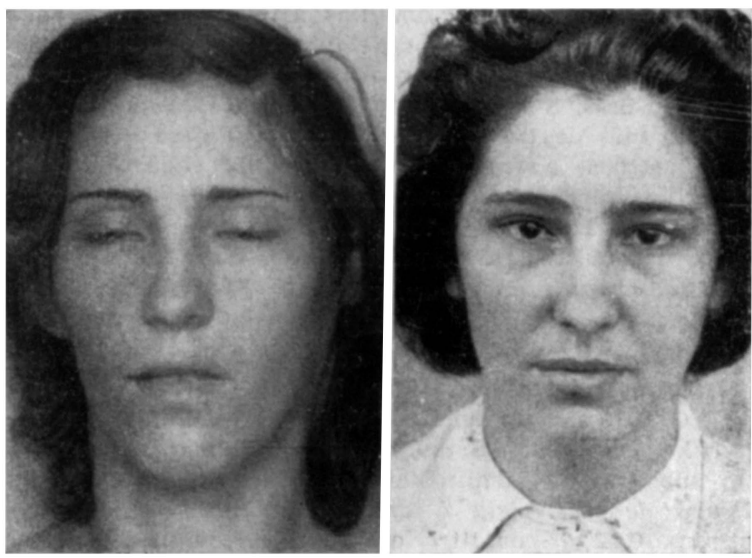

Fig. 1 - Caso 2 (A. B.). A esquerda, fotografia antes do tratamento pelo ACTH; à direita, fotografia após o término do tratamento pelo ACTH. 
Fig. 2 - Caso 3 (C. A. S.). A esquerda, fotografia antes do tratamento pelo $\mathrm{ACTH}$; à direita, fotografia logo após o térmíno do tratamento.
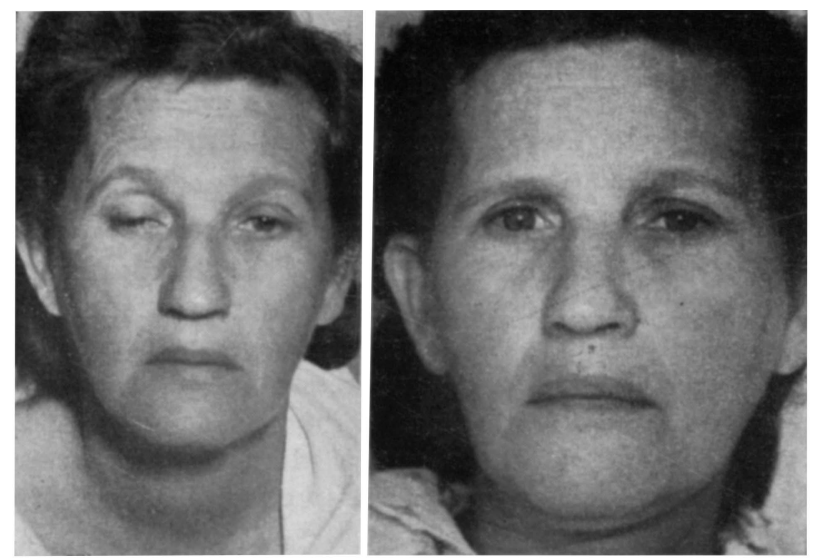

\section{COMENTÁRIOS}

Os três casos aqui relatados foram cuidadosamente escolhidos, uma vez que a miastenia grave é doença que pode apresentar remissões espontâneas: nos três a doença datava de mais de 2 anos e nenhum dêles apresentoı remissões espontâneas completas e duradouras.

Assim, no caso 1 a doença foi se agravando progressivamente sem qualquer remissão espontânea, apesar do uso intensivo da prostigmina. No caso 2 houve uma única remissão espontânea que durou apenas 45 dias no início da doença que, depois, se agravou progressivamente a ponto de ter sido feita a timectomia; nas últimas semanas que precederam a primeira internação não mais se obteve resposta eficiente à prostigmina, mesmo quando administrada em altas doses e por tôdas as vias; isso também foi verificado nas últimas semanas que precederam as duas reinternações ulteriores, constituindo um dos motivos mais importantes para novas administrações de ACTH. No caso 3 , após a fase aguda inicial, restaram, como manifestações permanentes, ptose das pálpebras, estrabismo divergente em OD e diplopia; êstes distúrbios jamais cederam ou melhoraram com qualquer das drogas anteriormente usadas.

Assim, os três casos se prestavam ao estudo que pretendiamos fazer e, em todos êles, o efeito do $\mathrm{ACTH}$ por via venosa foi extraordinàriamente benéfico; nos casos 1 e 2, no intervalo das séries de $\mathrm{ACTH}$, foi usada a cortisona com efeitos menos evidentes.

Nos casos 1 e 2 houve agravação perigosa dos sintomas na primeira semana do tratamento; contudo, a seguir, as melhoras tornaram-se satisfatórias e progressivas até a remissão da sintomatologia. A agravação mais séria ocorreu no caso 2 ; neste caso a respota ao hormônio foi sempre a mesma nas três séries: agravação da sintomatologia na primeira semana do tratamento e, a seguir, melhoras progressivas; nas duas primeiras séries houve remissão total; após a terceira série persistiram leve dificuldade para a oclusảo total das pálpebras e ligeiro distúrbio na deglutição. 
No caso 3 não houve agravação dos sintomas em qualquer etapa do tratamento; a diplopia e a ptose palpebral desapareceram, tendo havido correção do estrabismo. É de notar que esta oftalmoplegia jamais havia cedido anteriormente, de maneira completa, mesmo com o uso da prostigmina em dose adequada.

Nos três casos houve reaparecimento dos sintomas, em geral um mês após a suspensão do ACTH. No caso 3 reapareceram a diplopia e a ptose palpebral, porém de modo muito menos acentuado e, esta última, apenas observável em OD. No caso 2 reapareceram os mesmos sintomas anteriores que foram se agravando progressivamente. No caso 1 a sintomatologia foi piorando, porém sem atingir a intensidade verificada por ocasião da primeira internação. É de notar que a piora da doença se verificou, em todos os casos, apesar do emprêgo da prostigmina em doses adequadas, e depois elevadas.

O ACTH foi administrado em doses decrescentes de 25 até $2,5 \mathrm{mg}$. A via usada, nos 3 casos, foi a intravenosa, empregando-se como veículo o sôro glicosado isotônico (250 a $1000 \mathrm{ml}$ ) em gôta a gôta. Como coadjuvantes foram usados o cloreto de potássio nas doses de 2 até $10 \mathrm{~g}$ diárias e o sulfato de efedrina na dose de $25 \mathrm{mg} 3$ vêzes ao dia. A prostigmina também foi usada durante o tratamento, porém em doses muito menores do que nos intervalos de cada série de aplicação do hormônio. A dose máxima total de ACTH foi de $1057 \mathrm{mg}$ em 93 dias, e a mínima de $237,5 \mathrm{mg}$ em 22 dias. A dose de manutenção foi de $5 \mathrm{mg}$ em dias alternados para o caso 2 , e de 5 mg cada 3 dias para o caso 1 . O tratamento de manutenção foi feito durante mais de 40 dias, em regime de observação hospitalar. A paciente A. B. (caso 2) está sendo acompanhada, atualmente, em regime de ambulatório; o enfêrmo B. A. (caso 1) continua perfeitamente bem; a doente C. A. S. (caso 3) apresenta diplopia e moderada ptose palpebral em OD.

O ACTH constitui, pois, importante arma terapêutica para os casos maus de miastenia grave, devendo ser empregado em doses decrescentes pela via intravenosa; êste medicamento pode ser utilizado para tratamento de manutenção mediante o emprêgo de doses pequenas durante um tempo relativamente longo sem efeitos colaterais.

Acompanhamos, nestes últimos 2 anos, 5 casos de miastenia grave tratados pelo ACTH e cortisona, todos com resultados favoráveis e sem efeitos colaterais desagradáveis. Os efeitos da cortisona foram sensìvelmente inferiores aos obtidos com o hormônio adrenocorticotrófico.

\section{RESUMO}

São apresentados 3 casos de miastenia grave em que os recursos terapêuticos clássicos não deram resultado favorável. Os 3 pacientes foram, então, submetidos ao tratamento pelo ACTH e cortisona; em todos houve remissão da sintomatologia, remissão que perdurou até cêrca de um mês após a suspensão da hormonioterapia. O tratamento foi repetido várias vêzes de 
acôrdo com a evolução da doença. É de notar que em 2 pacientes (casos 1 e 2), foram estabelecidas doses minimas de manutenção controladas durante cêrca de 40 dias. O ACTH foi usado por via intravenosa em doses variáveis de 2,5 a $25 \mathrm{mg}$, diluido em 250 a $1000 \mathrm{ml}$ de sôro glicosado isotônico, na velocidade de 20 a 25 gôtas por minuto. Em todos os casos, durante a hormonioterapia, foi administrada prostigmina em doses muito pequenas.

\section{SUMMARY}

Myastenia gravis treated with ACTH and Cortisone. Report of three cases.

Three cases of myastenia gravis treated with ACTH and Cortisone after failure of classic therapy, are reported. All cases were symptoms free for about one month after withdrawall of hormone therapy. According to the evolution treatment was resumed several times. A minimal maintenance dosis was tried in cases 1 and 2, controled during a period of at least 40 days. ACTH was used intravenously (2.5 to $25 \mathrm{mgm}$. in 250 to $1,000 \mathrm{ml}$. isotonic glucose solution daily) at the rate of 20 to 25 drops per minute. Prostigmine was administered simultaneously in very small dosis. Serious relapse of symptoms occurred in the first week in each series of ACTH in case 2, and after the first series in case 1. All patients had a follow-up of two years.

\section{BIBLIOGRAFIA}

1. WALKER, M. B. - a) Case showing effect of prostigmin on myasthenia gravis. Proc. Roy. Soc. Med, 28:759 (abril), 1935; b) Treatment of myasthenia gravis with Physostigmine. Lancet, 1:1200 (junho 12), 1934. 2. WESTERBERG, M. R.; MAGEE, K. R. - Mestinon in the treatment of myasthenia gravis. Neurology, 4:762 (outubro), 1954. 3. WESTERBERG, M. R.; MAGEE, K. R.; SHIDEMAN, E. F. - Effect oi 3-hydroxyphenyldimethylamonium chloride (tensilon) in myasthenia gravis. Michigan M. Bull., 17:311, 1950. 4. WESTERBERG, M. R.; MAGEE, K. R.; SHIDEMAN, E. F. - Effect of Tensilon in myasthenia gravis. Neurology, 3:302 (abril), 1953. 5. OSSERMAN, K. E.; KAPLAN, L. I. - Rapid diagnostic test for myasthenia gravis increased muscle strenght, without fasciculations, after intravenous administration of edrophonium (tensilon) chloride. J.A.M.A., 150:265, 1952. 6. GROB, D.; HARVEY, A. M. - Observations on the effects of tetraethyl-pyrophosphate (TEPP) in man, and on its use in the treatment of myasthenia gravis. Bull. Johns Hopkins Hosp., 84: 532, 1949. 7. RIDER, J. A.; SHULMAN, S.; RICHTER, R. B.; MOELHER, H. C.; DUBOIS, K. P. - Treatment of myasthenia gravis with octamethyl-pyrophosphoramide. J.A.M.A., 145:967 (março 31), 1951. 8. SCHULMAN, S.; RIDER, J. A.; RICHTER, R. B. - Use of octamethyl-pyrophosphoramide in the treatment of myasthenia gravis. Further observations. J.A.M.A., 152:1707, 1953. 9. MINOT, A. S.; DODD, K.; RIVEN, S. S. - Use of guanidine hydrochloride in treatment of myasthenia gravis. J.A.M.A., 113:553 (agôsto 12), 1939. 10. MINOT, A. S.; DODD, K.; RIVEN, S. S. - The response of the myasthenia state to guanidine hydrochloride. Science, 87:348 (abril), 1938. 11. EDGEWORTH, H. - A report of progress on the use of ephedrine in a case of myasthenia gravis. J.A.M.A., 94:1146 (abril 12), 1930.12. TORDA, C.; WOLFF, H. G. - Effect of adrenocorticotrophic hormone of pituitary gland on ability of tissue to synthesize acetylcholine. Proc. Soc. Exper. Biol. \& Med., 57:137, 1944. 13. TORDA, C.; WOLFF, H. G. - Effect of blood serum from patients with myasthenia gravis on the synthesis of acetylcholine in vitro. J. Clin. Invest., 
23:649, 1944. 14. TORDA, C.; WOLFF, H. G. - Effects of organ extracts and their fractions on acetylcholine synthesis. Am. J. Physiol., 148:417, 1947. 15. TORDA, C.; WOLFF, H. G. - Effect of hypophysectomy on neuromuscular function. Am. J. Physiol., 156:274, 1949. 16. TORDA, C.; WOLFF, H. G. - Effects of adrenocorticotrophic hormone on neuromuscular function in patients with myasthenia gravis. $J$. Clin. Invest., 28:1228, 1949. 17. SOFFER, I. J. - Effects of adrenocorticotrophic hormone (ACTH) in myasthenia gravis with tumor of thymus. J. Mt. Sinai Hosp., 15:73, 1848. 18. MILlikAN, C. H.; EATON, L. M. - Clinical evaluation of the effect of ACTH and cortisone on myasthenia gravis. J. Lab. a. Clin. Med., 36:966, 1950. 19. MILlikAN, C. H.; EATON, L. M. - Clinical evaluation of ACTH and cortisone in myasthenia gravis. Neurology, 1:145 (marco), 1951. 20. SCHLEZINGER, N. S. Present status of therapy in myasthenia gravis. J.A.M.A., 148:508 (fevereiro 16), 1952. 21. TORDA, C.; WOLFF, H. G. - Effects of hypophysectomy and adrenocorticotrophic hormone on neuromuscular functions and acetylcholine synthesis. Am. J. Physiol., 161:534, 1950. 22. TORDA, C.; WOLFF, H. G. - Effects of administration of the adrenocorticotrophic hormone (ACTH) on patients with myasthenia gravis. Arch. Neurol. a. Psychiat., 66:163, 1951. 23. RITTER, J. A.; EPSTEIN, N. - Myasthenia gravis. Some observations on the effects of various therapeutic agents, including thymectomy and ACTH in nine year old child. Amer. J. Med. Sc., 220:66, 1950. 24. SHY, G. M.; BRENDLER, S.; RABINOVITCH, R.; MC EACHERN, D. Effects of cortisone in certain neuromuscular disorders. J.A.M.A., 144:1353, 1950.

Clínica Neurológica. Hospital das Clínicas da Fac. Med. da Univ. de São Paulo Caixa Postal 3461 - São Paulo, Brasil. 